\title{
Publisher Correction: Multiple fermion scattering in the weakly coupled spin-chain compound $\mathrm{YbAlO}_{3}$
}

\author{
S. E. Nikitin (1), S. Nishimoto (1D, Y. Fan, J. Wu (1), L. S. Wu, A. S. Sukhanov, M. Brando, N. S. Pavlovskii, J. Xu, \\ L. Vasylechko (1), R. Yu (1) \& A. Podlesnyak (1)
}

Correction to: Nature Communications https://doi.org/10.1038/s41467-021-23585-z, published online 14 June 2021.

The original version of this Article contained an error in ref. 20, which was incorrectly given with the wrong title as: “Agrapidis, C. E., van den Brink, J. \& Nishimoto, S. Ground state and low-energy excitations of the Kitaev-Heisenberg two-leg ladder. Phys. Rev. B 99, 224423 (2019)". The correct form of ref. 20 is: "Agrapidis, C. E., van den Brink, J. \& Nishimoto, S. Field-induced incommensurate ordering in Heisenberg chains coupled by Ising interaction: model for ytterbium aluminum perovskite YbAlO3. Phys. Rev. B 99, 224423 (2019)".

This has been corrected in the PDF and HTML versions of the Article.

Published online: 15 July 2021

\begin{abstract}
(c) Open Access This article is licensed under a Creative Commons Attribution 4.0 International License, which permits use, sharing, adaptation, distribution and reproduction in any medium or format, as long as you give appropriate credit to the original author(s) and the source, provide a link to the Creative Commons license, and indicate if changes were made. The images or other third party material in this article are included in the article's Creative Commons license, unless indicated otherwise in a credit line to the material. If material is not included in the article's Creative Commons license and your intended use is not permitted by statutory regulation or exceeds the permitted use, you will need to obtain permission directly from the copyright holder. To view a copy of this license, visit http://creativecommons.org/licenses/by/4.0/.
\end{abstract}

(C) The Author(s) 2021 